\title{
Carotenoid content of pandanus fruit cultivars and other foods of the Republic of Kiribati
}

\author{
Lois Englberger ${ }^{1,2 *} \dagger$, William Aalbersberg ${ }^{3}$, Usaia Dolodolotawake ${ }^{3}$, Joseph Schierle ${ }^{4}$, \\ Julia Humphries ${ }^{5}$, Tinai luta ${ }^{6}$, Geoffrey C Marks ${ }^{2}$, Maureen H Fitzgerald ${ }^{7}$, Betarim Rimon ${ }^{8}$ \\ and Mamarau Kaiririete ${ }^{8}$ \\ ${ }^{1}$ Island Food Community of Pohnpei, Pohnpei, Federated States of Micronesia: ${ }^{2}$ Division of International Health, \\ School of Population Health, University of Queensland, Brisbane, Australia: ${ }^{3}$ Institute of Applied Science, University \\ of the South Pacific, Suva, Fiji: ${ }^{4}$ DSM Nutritional Products Ltd, Kaiseraugst, Switzerland: ${ }^{5}$ University of Adelaide, \\ Faculty of Sciences, School of Agriculture and Wine, Glen Osmond, Australia: ${ }^{6}$ Ministry of Health and Medical \\ Services, Tarawa, Republic of Kiribati: ${ }^{7}$ School of Occupation and Leisure Sciences, University of Sydney, Sydney, \\ Australia: ${ }^{8}$ Ministry of Environment, Lands, and Agricultural Development, Tarawa, Republic of Kiribati
}

Submitted 1 March 2005: Accepted 10 August 2005

\begin{abstract}
Background: Kiribati, a remote atoll island country of the Pacific, has serious problems of vitamin A deficiency (VAD). Thus, it is important to identify locally grown acceptable foods that might be promoted to alleviate this problem. Pandanus fruit (Pandanus tectorius) is a well-liked indigenous Kiribati food with many cultivars that have orange/yellow flesh, indicative of carotenoid content. Few have been previously analysed.

Aim: This study was conducted to identify cultivars of pandanus and other foods that could be promoted to alleviate VAD in Kiribati.

Method: Ethnography was used to select foods and assess acceptability factors. Pandanus and other foods were analysed for $\beta$ - and $\alpha$-carotene, $\beta$-cryptoxanthin, lutein, zeaxanthin, lycopene and total carotenoids using high-performance liquid chromatography.

Results: Of the nine pandanus cultivars investigated there was a great range of provitamin A carotenoid levels (from 62 to $19086 \mu \mathrm{g} \beta$-carotene/100 g), generally with higher levels in those more deeply coloured. Seven pandanus cultivars, one giant swamp taro (Cyrtosperma chamissonis) cultivar and native fig (Ficus tinctoria) had significant provitamin A carotenoid content, meeting all or half of estimated daily vitamin A requirements within normal consumption patterns. Analyses in different laboratories confirmed high carotenoid levels in pandanus but showed that there are still questions as to how high the levels might be, owing to variation arising from different handling/preparation/analytical techniques.

Conclusions: These carotenoid-rich acceptable foods should be promoted for alleviating VAD in Kiribati and possibly other Pacific contexts where these foods are important. Further research in the Pacific is needed to identify additional indigenous foods with potential health benefits.
\end{abstract}

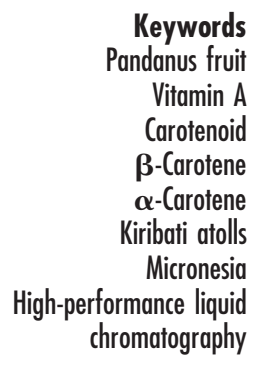

Vitamin A deficiency (VAD) is a serious problem in developing countries that mainly affects children and women, causing increased susceptibility to infections and problems with vision and eye health ${ }^{1}$. In communities with VAD and other nutritionally related diseases it is critical to identify and promote locally grown acceptable foods that may alleviate the problem and to understand the food beliefs and practices in the community ${ }^{2}$. The identification and promotion of nutrient-rich indigenous

†Correspondence address: PO Box 2299, Kolonia, Pohnpei 96941 FM, Federated States of Micronesia. foods also has importance for cultural preservation, import substitution and income generation.

The Republic of Kiribati (population 84 494), a remote nation of 33 atolls* widely scattered along the Equator in the central Pacific Ocean ${ }^{3}$, has a serious problem of VAD that was first identified in the late $1980 \mathrm{~s}^{4,5}$, with continuing unpublished health department reports. This problem

*An atoll is a ring-shaped low-lying coral island or group of islands, often consisting of only a narrow strip of land with seawater on both sides, circling a lagoon. reports of VAD disorders from health surveys ${ }^{6}$ and 
followed the migration from outer atolls to the urban centre of Tarawa and an increasing trend towards consuming imported processed foods ${ }^{6}$, the major item being rice, which contains no provitamin A carotenoid. Non-communicable diseases, including diabetes, heart disease and cancer, have also recently emerged as major public health problems and are associated with dietary and lifestyle changes ${ }^{7-9}$.

Kiribati faces a harsh environment with limited fresh water, making food production difficult. Furthermore, the islands are very low-lying with few places more than $2 \mathrm{~m}$ above sea level, making them vulnerable to sea-level rises, pollution and coastal erosion. Due to its high infant mortality rate $(62 / 1000)$, low per capita income and low access to safe drinking water and sanitation ( $47 \%$ and $46 \%$, respectively), Kiribati is classified as a Least Developed Country ${ }^{3}$.

Early studies indicated that the traditional diet was adequate and that there was no evidence of $\mathrm{VAD}^{10}$, but by the 1970s xerophthalmia (clinical signs of VAD including night blindness and Bitot's spots) was common ${ }^{11-13}$. A nationwide routine vitamin A supplementation programme was established in 1992, and horticulture programmes were initiated for encouraging the production and consumption of green leafy and other types of vegetables $^{13}$. However, vegetables are difficult to grow in an atoll environment. They also had not previously been part of the diet and were met with low acceptability ${ }^{13}$. People thought of green leafy vegetables as pig food ${ }^{14}$. Although there was some evidence of this vegetable promotion programme having an impact ${ }^{6}$, in general the attempts at introducing these foods into the dietary regime met with little success ${ }^{15}$.

\section{Cultural and dietary roles of pandanus, giant swamp taro and breadfruit in Kiribati}

Pandanus fruit, te kaina (Pandanus tectorius), which has the yellow, orange and red coloration indicative of carotenoid content, has been a very acceptable food for many years ${ }^{16,17}$. Pandanus is known as the second 'tree of life' after coconut ${ }^{18}$, due to the importance of the edible varieties for food and other varieties for weaving, handicrafts, building and medicine. Pandanus is also known as the ancestress-tree ${ }^{16}$ and Kiribati people were referred to by one writer as the "pandanus people, 16 . Preserved pandanus was formerly used to survive long sea voyages $^{17}$.

Owing to harsh atoll island climates, particularly in the southern islands of Kiribati, pandanus is among the few crops that can grow $^{19}$. To obtain edible fruits, vegetal propagation is necessary, by taking a cutting from a pandanus tree that bears edible fruits. The current collection of pandanus varieties has resulted from careful propagation by Kiribati people over past generations. Pandanus is a well-liked staple food, consumed raw or cooked in various recipes with different ingredients, including coconut cream. None the less, due to lifestyle changes and the increasing reliance on imported foods, there has been a great neglect of pandanus. This led to the Kiribati Pandanus Project ${ }^{20}$, initiated in 2001 for documenting, conserving and promoting Kiribati pandanus cultivars*. It was the basis for initiating this study.

Pandanus fruit is a composite fruit, called a bunch (or syncarp), which has many sections called keys (or phalanges) (Fig. 1) attached to an inner core. Pandanus bunches generally weigh from 9 to $14 \mathrm{~kg}^{21}$ and occasionally up to $30 \mathrm{~kg}^{22}$. A $14-\mathrm{kg}$ bunch may have approximately 50 keys, with the core and stem weighing approximately $1 \mathrm{~kg}^{21}$. The inner part of the key is chewed and sucked for its sweet pulp (Fig. 2), or the pulp may be extracted with a scraper (formerly shell, now metal). The nutrient-rich pulp is embedded in a highly fibrous mass, similar to some types of mangoes, and is hard work to consume. Boiling the keys makes the pulp more available and assists in the release of carotenoids from the cellular matrix, which may provide a greater amount of carotenoids compared with raw keys ${ }^{1}$. The outer part of the key is inedible. There is a great diversity of Kiribati pandanus, most reports suggesting that there are approximately 170 varieties ${ }^{16,19,22}$. Other reports list $200^{23}$ and 259 varieties $^{24}$, some of which are thought to be different names given for the same variety. Names are given according to taste, speed of ripening, seasonality and other local discretionary factors.

The only known nutrition studies of Kiribati pandanus fruit cultivars are one study using an older methodology and where cultivar names were not provided ${ }^{25}$ and a more recent analysis of preserved pandanus powder ${ }^{26}$. These studies did not include fresh, named cultivars, and thus provide little information relevant to the issues associated with the promotion of local pandanus cultivars to address VAD.

Giant swamp taro, te babai (Cyrtosperma chamissonis), is important in the diet as well as culturally in Kiribati foodgiving ceremonies. Along with coconut and pandanus, babai has been named among the three most important Kiribati indigenous foods ${ }^{22}$. There are around 20 cultivars $^{19}$. These vary by characteristics that include the colour of the edible corm (white to yellow). Unseeded and seeded breadfruit, te mai (Artocarpus altilis and Artocarpus mariannensis) and native fig, te bero (Ficus tinctora), have edible flesh with varying shades of yellow to orange coloration when ripe and are among the important indigenous Kiribati foods ${ }^{27}$. Apparently there are no previous studies assessing the carotenoid content of these foods from Kiribati.

Studies assessing the nutrient content of other Micronesian pandanus, giant swamp taro and breadfruit

*A cultivar refers to a variety produced by cultivation. In this paper, all pandanus cultivar names are capitalised for consistency with standard practices. 
Carotenoid content of Kiribati pandanus and other foods

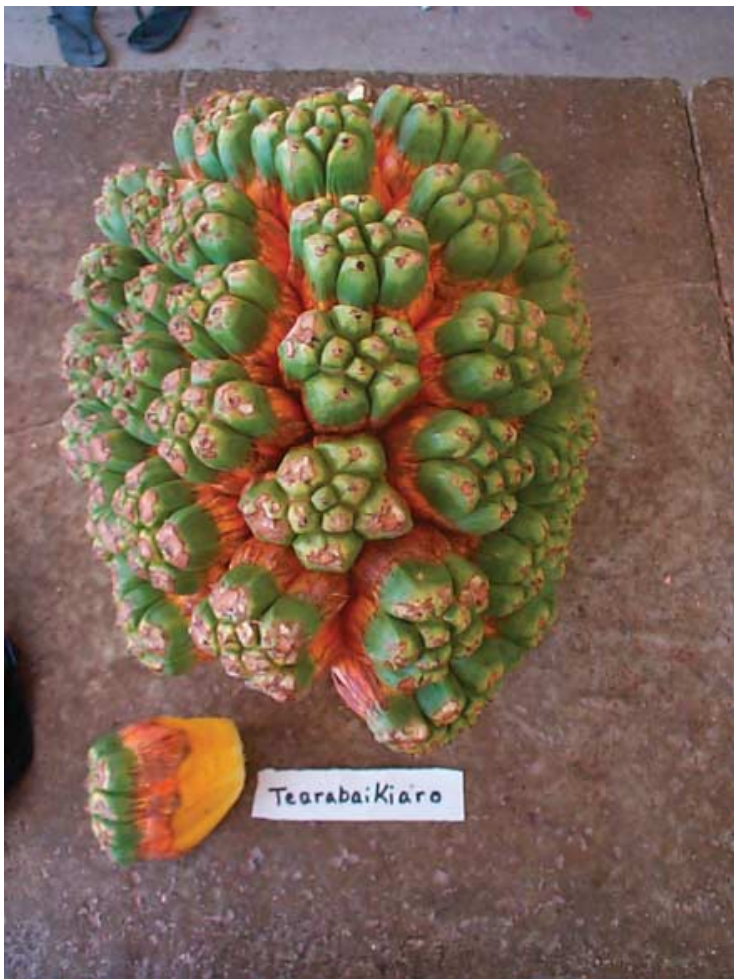

Fig. 1 A ripe pandanus bunch, Tearabaikiaro cultivar, and one key, showing the outer green inedible portion and the orangeyellow coloration of the edible portion

cultivars $^{28-30}$ show that the carotenoid content varies greatly among cultivars, with the greater carotenoid content found in those cultivars with the deepest coloration. The provitamin A carotenoids include $\beta$ carotene (the carotenoid making the greatest contribution to vitamin A activity), $\alpha$-carotene and $\beta$-cryptoxanthin ${ }^{1}$. Epidemiological studies show that the consumption of foods rich in other carotenoids, such as lutein, zeaxanthin and lycopene, protects against certain chronic diseases such as heart disease, certain cancers, diabetes and agerelated macular degeneration ${ }^{31-34}$, indicating that consuming these carotenoid-rich foods may have multiple health benefits.

Thus, the purposes of the present study were to: (1) identify carotenoid-rich Kiribati pandanus cultivars and other locally grown foods by analysing for $\beta$ - and $\alpha$-carotene, $\beta$-cryptoxanthin, lutein, zeaxanthin, lycopene, total carotenoids and water; (2) explore factors relating to the production, consumption and acceptability of these foods; and (3) assess their potential for alleviating VAD.

\section{Methods}

Ethnographic methods $2,30,35,36$, including key informant interviews (face-to-face), informal focus group discussions, observations, photography, literature review and

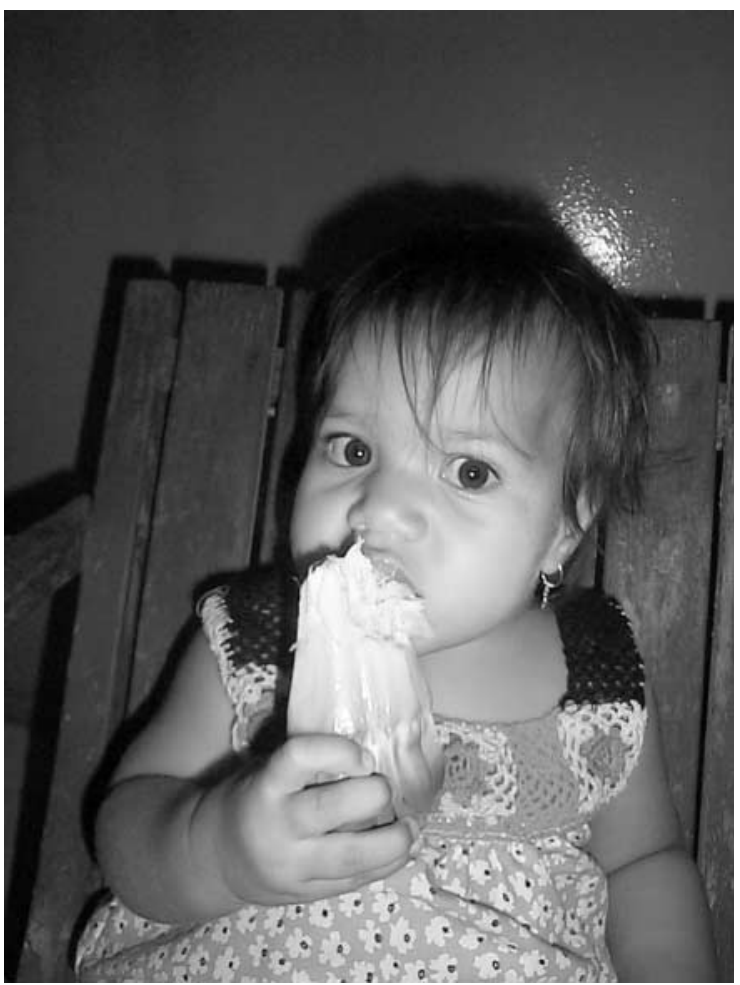

Fig. 2 Young child chewing and sucking on a pandanus key for its sweet pulp

structured collection of pandanus samples, were used to more fully characterise the cultivars and samples collected.

The sample data collection kit included: a formatted documentation list and interview guide; labelling tape; sample labels; zip-lock sample bags; a labelling marker; the DSM Yolk Colour Fan; a digital camera; Soehnle electronic kitchen scales (accurate to $2 \mathrm{~g}$ ); a measuring tape; and a vacuum-pack sealing machine (FoodSaver Vac 750/Ultra).

\section{Material}

Data collection focused on South Tarawa of Tarawa Atoll, due to geographic dispersion of the atolls, irregular flights and boats, and limited resources to collect data and samples from outer atolls. This is an urbanised area compared with the rest of Kiribati and more dependent on imported food due to lack of land, thereby affecting the data and information collected. As Kiribati is a highly dispersed set of atolls on both a north/south as well as an east/west axis, seasonality greatly varies from atoll to atoll, which also affects the types and varieties of foods grown.

\section{Selection, documentation and preparation of samples}

The lead author, assisted by local government officers, carried out the data collection during two visits to Tarawa, Kiribati, in September 2003 and May 2004. The criteria for selecting the samples were that the foods were indigenous and had a yellow, orange or orange-red coloration 
indicative of carotenoid content. Some cultivars with lighter coloration were collected for comparison purposes. Most samples were collected from two local produce markets, Bikinibeu and Bairike Markets, with two samples collected directly from growers.

The sampling plan included collecting at least six goodquality pandanus keys or three or more fruits or corms or berries of the other foods per composite sample to provide a representative sample. Due to the large size of the inedible portion of the pandanus key, limited space and weight for transporting the frozen samples, and the need to avoid confusion among laboratory analysts who may not be familiar with what part of the pandanus key is edible, only edible portions were included in the composite sample. For pandanus, the edible portion of each key was cut off, then cut again in order to provide equal portions from each key and to prepare two replicate sets of composite samples, one set each for two study laboratories. For the taro, breadfruit and pumpkin, equal portions from each corm or fruit were selected to make the composite sample. For the composite sample of berries, sufficient berries were selected to make 1 cup.

The cooking procedures were standardised, using the type of cooking normally used for the particular food and carried out by the primary author in most cases. All raw pandanus samples were boiled for about $30 \mathrm{~min}$, whereas the preserved pandanus samples were cooked and prepared on outer atolls with the reported cooking time being about an hour. The fresh pandanus samples were frozen immediately after bagging.

The pandanus cultivar names were obtained from the local market sellers or growers from whom the samples were collected. Local food experts were contacted to confirm the identification. Measurements were taken of the length of the whole pandanus key (from the top of the inedible portion to the bottom of the edible portion), its girth (widest point around the key) and weight of the whole key (including the inedible and edible portion).

Digital photographs of the pandanus plants, bunches and keys and other foods were taken in order to assist in identifying and documenting the cultivars. Marshall Islands pandanus photographs were used to assist in identifying Kiribati cultivars that are also growing in the Marshall Islands, but are known by different names.

The coloration of the edible portion of the pandanus key and other food samples was assessed visually as yellow, orange or orange-red coloration, and then estimated by the DSM (formerly Roche) Yolk Colour Fan in order to standardise the description of coloration. This fan, developed for objectively judging egg yolk colour ${ }^{37}$, is composed of 15 segments of increasing intensities of yellow, orange and orange-red numbered from 1 to 15 .

To prepare pandanus samples, the inedible key portion was cut off and discarded; the soft edible portions were packed in zip-lock plastic bags, identifying by cultivar name, number of keys (or fruits, corms or berries), sample collection date, maturity and processing (if raw or cooked, how cooked and how long). The other food samples were prepared in a similar way, preparing samples cooked or raw, as normally consumed.

\section{Sample allotments, storage and transport to the laboratory}

As there are no facilities for nutrient analysis in Kiribati, the samples were frozen and transported (continuous coldchain using frozen gel-ice packs) to overseas laboratories. The Institute of Applied Sciences/University of the South Pacific (IAS/USP), Fiji, and the DSM Nutritional Products laboratory, Switzerland, provided the comprehensive set of results and are the basis for the major interpretation. Some samples were analysed at the University of Adelaide laboratory in Australia to assess how sensitive the results would be to differences in preparation/handling/analytical techniques.

For pandanus samples collected in 2004, the edible portion of each key was cut in half and replicate samples were prepared for the IAS/USP and Australian laboratories. Storage and transport of the sample sets were similar: preparing the samples and hand-carrying (continuous cold-chain) to the laboratories. However, the samples sent to IAS/USP were frozen in zip-lock bags with air removed manually; the samples sent to the Australia laboratory were prepared and transported first to Pohnpei, Micronesia, re-packed using vacuum sealing, frozen/ stored and then transported to the laboratory. Quarantine requirements for sample transport were fully met.

\section{Chemical analysis}

The primary laboratory (IAS/USP, Fiji) used standard carotenoid analysis procedures ${ }^{38}$, including high-performance liquid chromatography (HPLC). The extraction, separation, identification and quantification methodologies of the Fijian and Swiss laboratories are described previously $^{28,39}$. As for the primary laboratory, the food sample was exhaustively extracted with acetone and filtered. The organic layer was evaporated at low temperature and pressure, using nitrogen gas to remove all traces of solvent. After filtering through a $0.45 \mu \mathrm{m}$ HPLC filter paper into a volumetric flask, the extract was made to an appropriate volume (depending on expected concentration) with methanol. An appropriate sample volume (usually $25 \mu \mathrm{l}$ ) was injected onto a Novapak C18 $(3.9 \mathrm{~mm}$ internal diameter $\times 300 \mathrm{~mm}$ length) stainless-steel column with C18 guard column. The mobile phase was methanoltetrahydrofuran (90:10) flowing at $0.5 \mathrm{~cm}^{3} \mathrm{~min}^{-1}$ using a Waters model 510 pump. The ultraviolet detector (a Waters 461 spectrophotometer) was set at $450 \mathrm{~nm}$, with $\alpha$ - and $\beta$-carotene eluting at about 30 and $32 \mathrm{~min}$, respectively. The concentration of standards was determined by measuring the absorbance of the $\beta$-carotene at $463 \mathrm{~nm}$ and using Beer's law with a molar absorptivity of 125893 . All analyses were carried out in duplicate with the mean 
reported (results must vary by less than 10\%). Blanks and recovery samples were run as quality assurance methods. A set of analyses was accepted if recoveries were in the range $80-120 \%$. The sum of total carotenoids was estimated by comparing the sum of their peak areas with that of $\beta$-carotene.

The extraction methodology of the Australian laboratory used saponification, converting carotenoid esters to their parent hydroxycarotenoids ${ }^{40}$. The carotenoid analyses were performed on an Agilent Technology model 1050 HPLC system equipped with a quaternary solvent delivery system, a 1050 autosampler, a thermostatted column compartment and a 1050 diode array detector. Separations were carried out on a silica-based nitrile-bonded $(25 \mathrm{~cm}$ length $\times 4.6 \mathrm{~mm}$ internal diameter; $5 \mu \mathrm{m}$ spherical particle) column (Regis Chemical, Morton Grove, IL, USA) protected with a Brownlee nitrile-bonded guard cartridge $(3 \mathrm{~cm}$ length $\times 4.6 \mathrm{~mm}$ internal diameter; $5 \mu \mathrm{m}$ particle size). The separation, identification and quantification of the major carotenoid constituents were determined by normal-phase HPLC and are described by Khachik et al. ${ }^{41}$. $\beta$-Apo- $8^{\prime}$-carotenal was used as the internal standard with 99\% recovery. The results are a mean of three replicates. The Australian laboratory participated in the HarvestPlus carotenoid proficiency test early in 2005, all groups analysing three samples in triplicate for $\beta$ - and $\alpha$-carotene, lutein and zeaxanthin. All results of the Australian laboratory were within the average ranges of the other groups.

From the time of sample collection until the time of sample analysis by the laboratory, there were less than two months of frozen storage for the samples sent to Fiji, about six months for those sent to Switzerland, and four months for those sent to Australia.

\section{Assessment of carotenoid content and impact on vitamin A requirements}

In order to assess all pandanus cultivars and avoid interlaboratory data differences (see below), this assessment used the Fiji laboratory results. The number of keys needed to meet estimated vitamin A requirements ${ }^{42}$ was calculated using the mean weight of the edible portion per key and the $\beta$-carotene equivalents/100 g per cultivar. The calculations were made for non-pregnant, non-lactating women and children aged 1-10 years. Pregnant and lactating women and young children are particularly vulnerable to VAD and the VAD disorder of night blindness, which can be combated by provision of vitamin $\mathrm{A}^{1}$.

The $\beta$-carotene equivalent value was calculated from the HPLC analyses by adding the $\beta$-carotene content and half of the sum of the $\alpha$-carotene and $\beta$-cryptoxanthin content. Retinol equivalents (RE) were calculated as onesixth of $\beta$-carotene equivalents, according to the conversion factor $6 \mu \mathrm{g} \beta$-carotene to $1 \mu \mathrm{g}$ retinol $^{42}$. Retinol activity equivalents (RAE) were also calculated, using the newly advised conversion factor of 12:1 for $\beta$-carotene equivalents ${ }^{43}$.

\section{Results and discussion}

Samples of nine pandanus cultivars were obtained, varying by size, appearance, coloration, taste and carotenoid level. Cultivar seasonality also varied, as seen by the market surveys, with mostly different cultivars present in the two different collection periods (September 2003 and May 2004). Also, samples were collected of two types of preserved pandanus, two giant swamp taro cultivars, native fig, three breadfruit cultivars and one pumpkin cultivar.

\section{Reconciliation for spellings}

The spellings of pandanus cultivars and other foods were reconciled with those in the literature ${ }^{20,22,24,44}$. Pandanus names often begin with 'te ara', which literally means 'the name'. Another common prefix to pandanus names is 'te iri', which refers to the pandanus itself as a particular type. Luomala $^{22}$ points out that the prefix 'ani' is common, but that there is no apparent pattern of naming pandanus: they can be named for mythical lands, deities, colours, places and qualities. Informants pointed out that some pandanus cultivars may be known by two names, one with the prefix and one without, but that it is always correct to use the prefix.

\section{Assessment of carotenoid content of pandanus fruit cultivars}

For the nine pandanus cultivars the carotenoid levels ranged from 62 to $896 \mu \mathrm{g} \beta$-carotene/100 g (Fiji laboratory) (Table 1). There was excellent agreement between the Fijian and Swiss laboratories on $\beta$-carotene content of the preserved pandanus paste and powder (Fig. 3), with differences less than $60 \mu \mathrm{g}$ (Table 1). The carotenoid levels (including lutein and zeaxanthin) in the preserved pandanus paste, te tuae, were relatively high despite the fact that this product was sun-dried, a processing known to destroy carotenoid content ${ }^{45}$. On the other hand, the preserved pandanus powder, te kabubu, contained low carotenoid levels; very likely due to the greater severity of the processing treatment. Kumar et al. ${ }^{26}$ also found low carotenoid levels in their analysis of Kiribati preserved pandanus powder (22 $\mu \mathrm{g} \beta$-carotene equivalents/100 g). Consistent with other studies showing that riper fruits have higher carotenoid levels ${ }^{45}$, the ripe Tearaonimaai contained significantly higher levels than the half-ripe Tearaonimaai pandanus and the ripe native fig (te bero) also had higher levels than the half-ripe sample (Tables 1 and 2). There were too few sample sets of raw cultivar versus cooked cultivar to determine the effect of cooking on carotenoid content for these samples.

The carotenoid levels of the five pandanus cultivars analysed by the Australian laboratory ranged from 548 to 


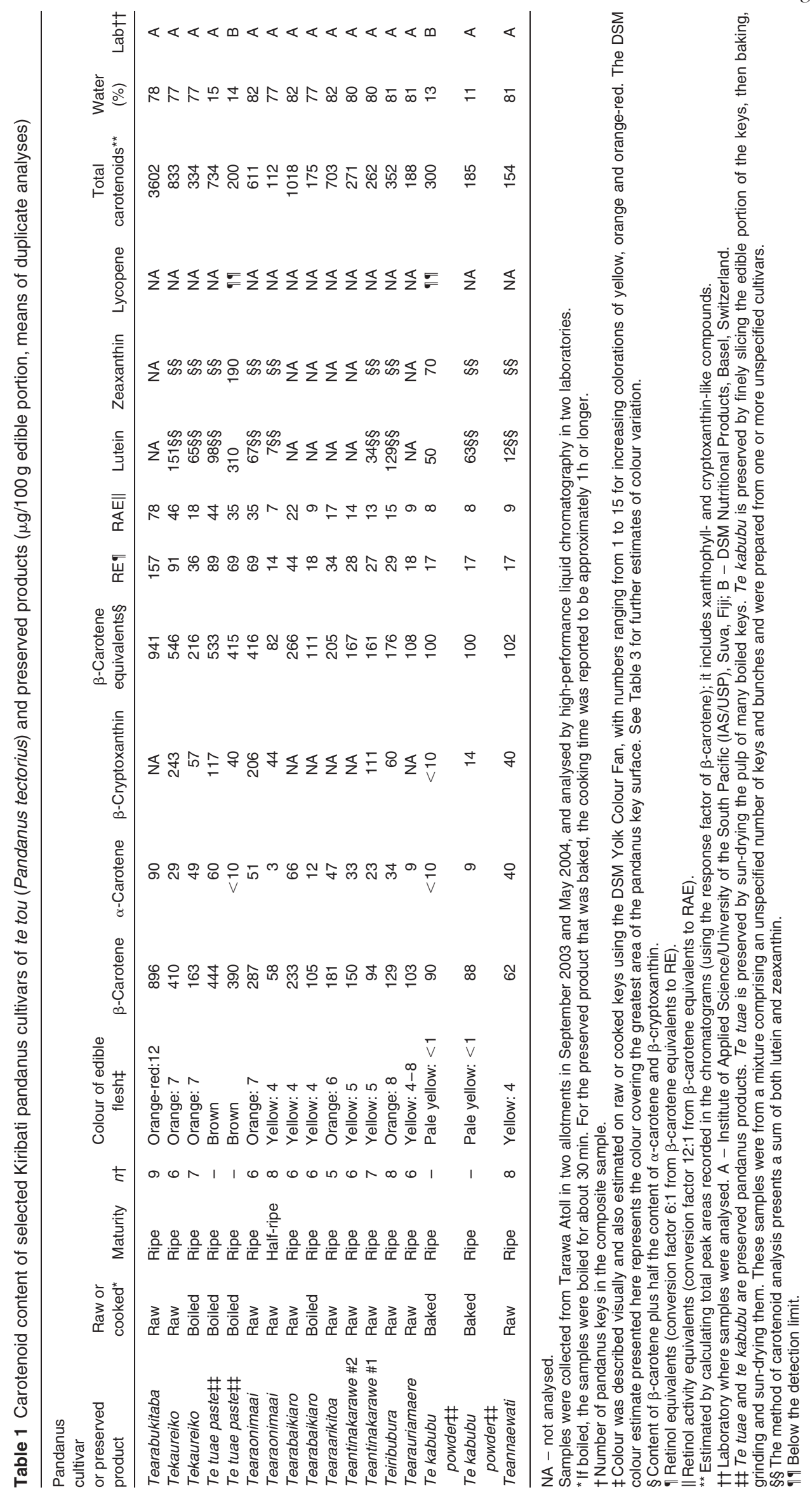




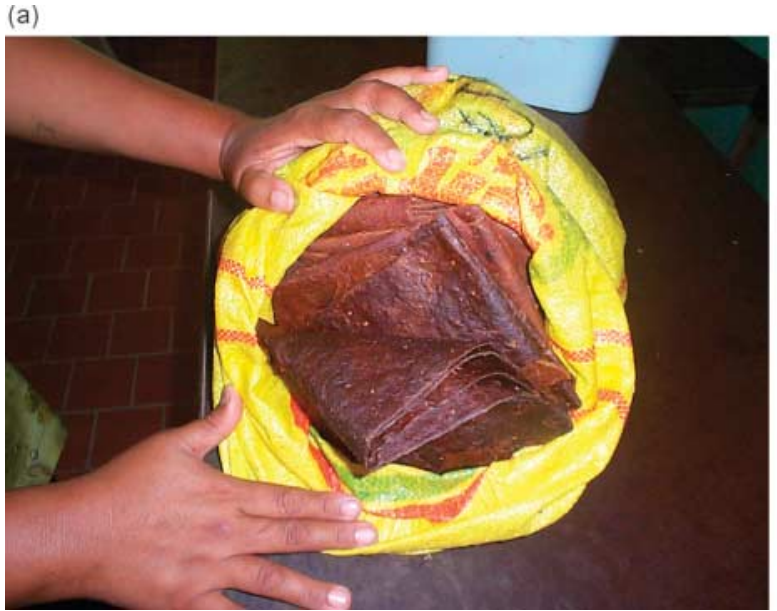

(b)

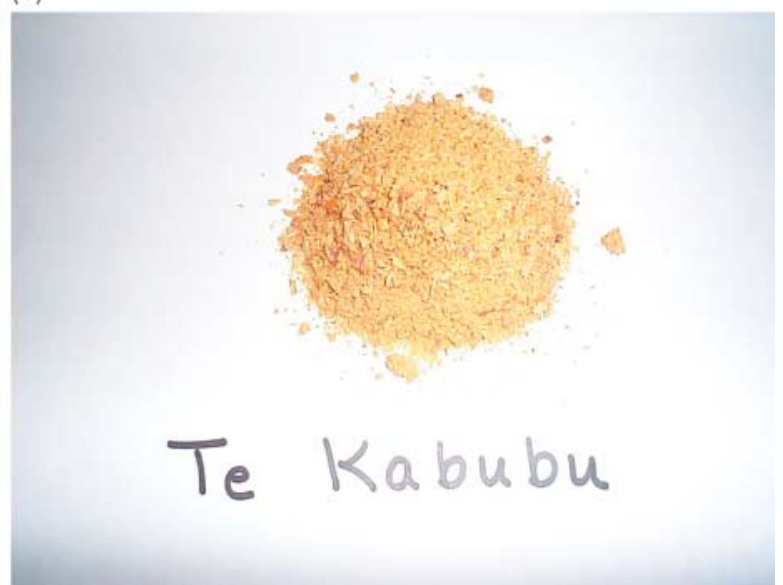

Fig. 3 The deep brown-coloured preserved pandanus paste, te tuae, folded in sheets ready for sale (a) and the pale yellow-coloured preserved pandanus powder, te kabubu, ready for mixing in water for a drink (b)

$19086 \mu \mathrm{g} \beta$-carotene/100 g (Table 3), considerably higher than those of the other laboratories. This shows how sensitive laboratory results can be in terms of handling, preparation and analytical techniques. Despite the differences, the carotenoid levels are still high, the unresolved question being exactly how high.

Of those other foods analysed in addition to pandanus, the native fig, Te Katutu giant swamp taro cultivar and pumpkin had carotenoid levels similar to and exceeding those of some of the pandanus cultivars, including lutein and zeaxanthin. In contrast to all other samples, the ripe native fig contained lycopene; the level was relatively high. The Te Mai Kora seeded breadfruit cultivar did not contain high provitamin A carotenoid levels compared with the pandanus, but it contained higher levels than the other breadfruit cultivars and its level of lutein/zeaxanthin was higher than that of the pandanus cultivars. The seeded breadfruit sample was ripe, as it is consumed ripe, whereas the other two breadfruit cultivar samples were at the mature stage (ready to eat, but not ripe) as they are generally eaten at that stage. Possibly the other two breadfruit cultivars would also contain higher carotenoid levels if analysed at the ripe stage.

In general the deeper coloured pandanus cultivars and other foods with deeper coloured edible portions had

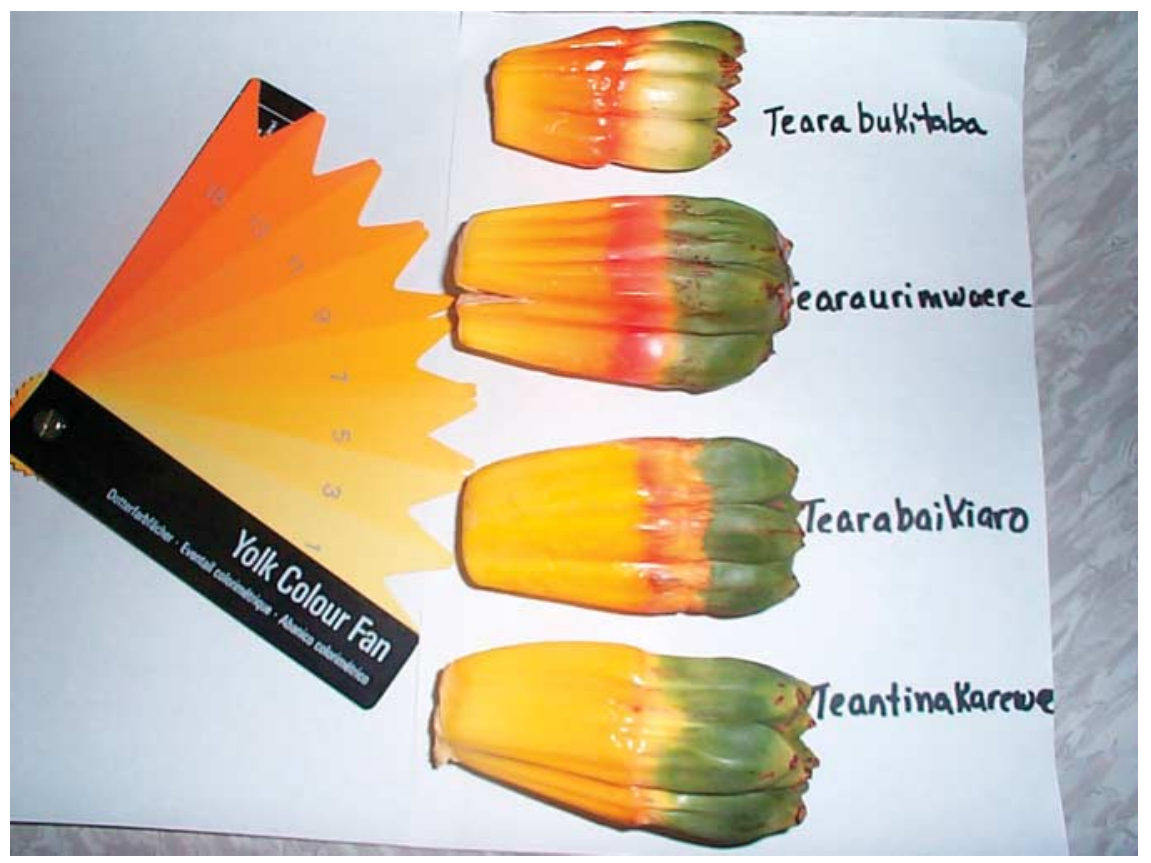

Fig. 4 Comparison of four pandanus cultivars with the DSM Yolk Colour Fan, with the Tearabukitaba cultivar showing with the greatest coloration 
higher carotenoid levels, as assessed visually and estimated using the DSM Yolk Colour Fan (Fig. 4), although sometimes colour estimates were difficult due to the subtle shades of coloration. The fan's small size facilitated its use in the field and the fan colours matched well to the pandanus fruit and other foods analysed.

\section{Assessment of impact of pandanus cultivars and other foods on vitamin A requirements}

Of the nine pandanus cultivars analysed, eight were assessed for their impact on meeting vitamin A requirements (Table 4), comparing the carotenoid levels and key size to determine the number of keys needed for meeting vitamin A requirements (one cultivar was not assessed for this as measurements of its keys were not taken).

A previous study ${ }^{21}$ showed that consuming up to 50 pandanus keys was within the normal pattern of adult consumption and that 2- to 3-year-old children commonly consumed up to 10 keys per day, thus providing a standard for the limits of normal pandanus consumption.

Of the eight pandanus cultivars assessed, seven were found to contain carotenoid levels that could meet the total estimated vitamin A requirement for non-pregnant, non-lactating women, within the normal patterns of consumption. Three cultivars contained levels sufficient to meet the total child (2-5 years old) estimated vitamin A requirement within normal patterns of consumption.

In assessing the potential impact of consumption of the native fig (te bero) and Te Katutu giant swamp taro cultivar on meeting estimated daily vitamin A requirements, a comparison can be made to the amount of local starch foods eaten traditionally by Pacific Islanders. This is estimated at 750-1000 g daily ${ }^{46}$. If a non-pregnant, nonlactating woman ate $1000 \mathrm{~g}$ of either te bero or Te Katutu, she could obtain over half her estimated vitamin A requirements. A similar comparison for 2-5-year-old children, who may eat $250 \mathrm{~g}$ per day, shows that these two foods might contribute to slightly less than a quarter of estimated vitamin A requirements, a smaller but important contribution. Women and children do not normally eat pumpkin and raw seeded breadfruit in such large quantities and so the impact of consumption of these foods on vitamin A status would be less, although still adding to overall intake. Bioavailability studies have not yet been carried out on these foods; these are still needed in order to confirm the contribution of the foods to meeting vitamin A requirements.

\section{Assessment of availability and acceptability}

All nine pandanus cultivars were highly acceptable, as confirmed by key informants providing information on the different cultivars (Table 5). Informants noted that although some cultivars produce a slight itchy sensation in the throat after consumption, this may be avoided by first cooking the pandanus. Some cultivars (such as Teantinakarewe) were more popular and well-known. 


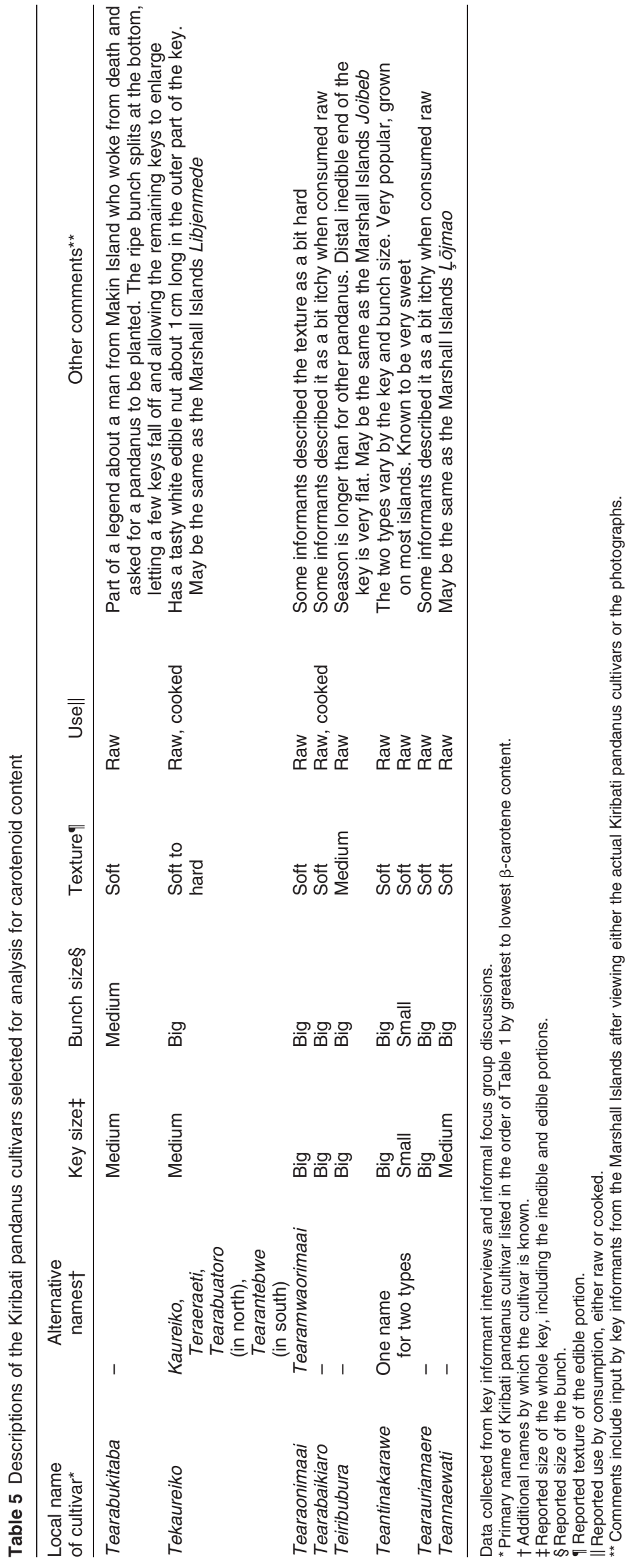


Informants also pointed out that the different atolls are known for specific pandanus cultivars and that availability of the cultivars is not easy to specify, as some cultivars may be common on one island but rare on another.

The yellow-fleshed Te Katutu was reported as well-liked but less tasty than the white-fleshed giant swamp taro Te Ikarao $^{19}$. According to key informants and the literature, te bero is often looked upon as a last resource food ${ }^{27}$, but it was marketed at the time of this data collection and showed high acceptability. The te bero berry ( $1-2 \mathrm{~cm}$ in diameter) is a starchy fruit with yellow-orange coloration; berries are cooked, mashed and eaten cooked in several recipes, and are also dried and stored ${ }^{18}$. This food might offer particular potential for people on the southern islands, where there are harsh growing climates and food shortages. The yellowfleshed ripe breadfruit Te Mai Kora is a popular snack and is potentially a nutritious addition to the diet.

\section{Conclusions}

As far as the authors are aware, this is the first systematic screening of Kiribati pandanus cultivars and other Kiribati foods for carotenoid content using HPLC. The results of the primary study laboratory (Fiji) showed that seven Kiribati pandanus cultivars, one taro cultivar and native fig, all culturally acceptable, contain significant levels of provitamin A carotenoids capable of meeting all or half of estimated daily vitamin A requirements for non-pregnant, non-lactating adult women within normal consumption patterns. The seeded breadfruit and pumpkin contain moderate carotenoid levels for contributing to the overall dietary intake and are important on atoll island environments where vitamin A sources are scarce. Thus, these acceptable carotenoid-rich foods should be promoted for alleviating VAD. The results of the Australian laboratory confirm that preparation, handling and analytical techniques can alter the exact estimates quite significantly, so comparison of data between this and other similar papers needs to be done with this in mind and interpreted accordingly.

The ethnographic approach to selecting cultivars for the study and collecting data relating to production, consumption and acceptability factors is also essential in the process of developing food-based strategies for alleviating VAD. Finally, the approach may be of importance in planning dietary improvement in other Pacific contexts where there has been a significant shift from indigenous to imported foods and/or there is evidence of VAD.

\section{Acknowledgements}

The people of Kiribati are warmly thanked for providing information on the pandanus and other foods, including officers of the Agriculture Division of the Ministry of Environment, Lands, and Agricultural Development, the Ministry of Health and Medical Services, AMAK Women's
Association and Tebuntamaneaba Primary School, in particular Tianeti Ioanne, Tokamai Tokintekai, Maio Tebania, Tokintekai Bakineti and Teebure Tiroia. The Secretariat of the Pacific Community, Pacific Agricultural Plant Genetic Resources Network, SPRIG, United Nations Children's Fund, Centers for Disease Control and Prevention, Sight and Life, and the Food and Agriculture Organization of the United Nations are thanked for funding and advisory support. Dr Martin Frigg is warmly thanked for his guidance and support throughout the project.

\section{References}

1 McLaren DS, Frigg M. Sight and Life Manual on Vitamin A Deficiency Disorders (VADD), 2nd ed. Basel, Switzerland: Task Force Sight and Life, 2001.

2 Kuhnlein HV, Pelto GH, eds. Culture, Environment, and Food to Prevent Vitamin A Deficiency. Boston, MA: International Nutrition Foundation for Developing Countries, 1997.

3 United Nations. Common Country Assessment: Kiribati. Suva, Fiji: Office of the United Nations Resident Coordinator, 2002 .

4 Schaumberg DA, Linehan M, Hawley G, O'Connor JO, Dreyfuss M, Semba RD. Vitamin A deficiency in the South Pacific. Public Health 1995; 109(3): 311-7.

5 Danks J, Kaufman D, Rait J. A clinical and cytological study of vitamin A deficiency in Kiribati. Australian and New Zealand Journal of Ophthalmology 1992; 20: 215-8.

6 Government of Kiribati. A Situation Analysis of Children, Youth and Women in Kiribati. Suva, Fiji: United Nations Children's Fund, 2002.

7 Schaumberg DA, O'Connor J, Semba RD. Risk factors for xerophthalmia in the Republic of Kiribati. European Journal of Clinical Nutrition 1996; 50(11): 761-4.

8 King H, Taylor R, Zimmet P, Pargeter K, Raper LR, Beriki T, et al. Non-insulin-dependent diabetes (NIDDM) in a newly independent Pacific nation: the Republic of Kiribati. Diabetes Care 1984; 7(5): 409-15.

9 Taylor R, Badcock J, King H, Pargeter K, Zimmet P, Fred T, et al. Dietary intake, exercise, obesity and noncommunicable disease in rural and urban populations of three Pacific island countries. Journal of the American College of Nutrition 1992; 11(3): 283-93.

10 Coyne T. Lifestyle Diseases in Pacific Communities. Noumea, New Caledonia: Secretariat of the Pacific Community, 2000.

11 Holmes S. Nutrition Survey in the Gilbert Islands. Suva, Fiji: South Pacific Health Services, 1953.

12 Willmott JV. Nutrition of Gilbertese children. South Pacific Bulletin 1970; (Second Quarter): 25-7.

13 Jansen AAJ. Report on a Visit to Gilbert and Ellice Islands: 5 June-8 August 1971. Manila: World Health Organization, 1971.

14 Barker C. Review of the Family Food Production and Nutrition Project. Report prepared for the UNICEF Pacific Programme Office, Suva, Fiji, 21 July-30 September 1995. Suva, Fiji: United Nations Children's Fund, 1996.

15 Sisifa A. Strategy for National Agricultural and Fisheries Development: Horizon 2010 for the Republic of Kiribati. Rome: Food and Agriculture Organization of the United Nations, 2002.

16 Grimble A. The migrations of a Pandanus people: as traced from a preliminary study of food, food-traditions, and food-rituals in the Gilbert Islands. Journal of the Polynesian Society 1933; Memoir No. 12(Instalment No. 1): 1-50.

17 Koch G. The Material Culture of Kiribati. Translated by Slatter $\mathrm{G}$ from the original manuscript in German [Materielle 
Kultur der Gilbert-Inseln]. Suva, Fiji: Institute of Pacific Studies of the University of the South Pacific, 1986.

18 Barako E, Io B. Itubaang: Plants of Kiribati and their Uses. Bairiki, Tarawa, Kiribati: The Foundation for the Peoples of the South Pacific, 2002.

19 Small CA. Atoll Agriculture in the Gilbert and Ellice Islands: Department of Agriculture, Tarawa. Hong Kong: Fotographics International Publishers, 1972.

20 Natake T, Beingam M. Progress Report: Kiribati Pandanus Project June-September 2002. Tanaea, South Tarawa, Republic of Kiribati: Agriculture Division, Ministry of Natural Resources Development, 2002.

21 Murai M, Pen F, Miller CD. Some Tropical South Pacific Island Foods. Description, History, Use, Composition, and Nutritive Value. Honolulu, HI: University of Hawaii Press, 1958.

22 Luomala K. Ethnobotany of the Gilbert Islands. Bernice P Bishop Museum, Bulletin 213. New York: Kraus Reprint Co., 1971.

23 Thaman RR. Kiribati agroforestry: trees, people and the atoll environment. Atoll Research Bulletin 1990; 333: 2-29.

24 Sabatier E. Gilbertese-English Dictionary. Originally compiled in French by Father E Sabatier (1939) and translated by Sister Oliva of the Catholic Mission, Tarawa (1971). Sydney, Australia: South Pacific Commission Publications Bureau, 1971.

25 Peters FE. The Chemical Composition of South Pacific Foods. Technical Paper No. 115. Noumea, New Caledonia: South Pacific Commission, 1958.

26 Kumar S, Aalbersberg W, English RM, Ravi P. Pacific Islands Foods Volume 2. Nutrient Composition of Some Pacific Island Foods and the Effect of Earth-oven Cooking. Suva, Fiji: Institute of Applied Sciences, University of the South Pacific, 2001.

27 Baiteke C. The cultural approach to atoll agriculture. In: Chase RG, ed. Review of Agricultural Development in the Atolls. Invited papers presented at the Workshop on 'Developing an Agricultural Research Program for the Atolls', Pacific Harbour, Fiji, 19-23 November 1990. Apia, Western Samoa: University of the South Pacific, 1992.

28 Englberger L, Aalbersberg W, Fitzgerald MH, Marks GC, Chand K. Provitamin A carotenoid content and cultivar differences in edible pandanus fruit Pandanus tectorius. Journal of Food Composition and Analysis 2003; 16(2): 237-47.

29 Englberger L, Aalbersberg W, Ravi P, Bonnin E, Marks GC, Fitzgerald $\mathrm{MH}$, et al. Further analyses on Micronesian banana, taro, breadfruit and other foods for provitamin A carotenoids and minerals. Journal of Food Composition and Analysis 2003; 16(2): 219-36.

30 Englberger L, Aalbersberg W, Schierle J, Marks GC, Fitzgerald $\mathrm{MH}$, Muller $\mathrm{F}$, et al. Carotenoid content of different edible pandanus fruit cultivars of the Republic of the Marshall Islands. Journal of Food Composition and Analysis 2006; 19: 484-94.

31 Bertram JS. Lectures presented at the 13th International Symposium on Carotenoids held in Honolulu, Hawaii, USA, 6-11 January 2002. Pure and Applied Chemistry 2002; 74(8): $1369-478$.

32 Ford ES, Will JC, Bowman BA, Narayan KM. Diabetes mellitis and serum carotenoids: findings from the Third National
Health and Nutrition Examination Survey. American Journal of Epidemiology 1999; 149(2): 168-76.

33 World Cancer Research Fund. Food, Nutrition and the Prevention of Cancer: A Global Perspective. Washington, DC: American Institute for Cancer Research, 1997.

34 Mares-Perlman JA, Millen AE, Ficek TL, Hankinson SE. The body of evidence to support a protective role for lutein and zeaxanthin in delaying chronic disease Overview. Journal of Nutrition 2002; 132(3): 518S-24S.

35 Blum L, Pelto PJ, Pelto GH, Kuhnlein HV. Community Assessment of Natural Food Sources of Vitamin A: Guidelines for an Ethnographic Protocol. Ottawa: International Development Research Centre, 1997.

36 Englberger L, Fitzgerald MH, Marks GC. Pacific pandanus fruit: an ethnographic approach to understanding an overlooked source of provitamin A carotenoids. Asia Pacific Journal of Clinical Nutrition 2003; 12(1): 38-44.

37 Vuilleumier JP. The Roche yolk colour fan - an instrument for measuring yolk colour. Poultry Science 1969; 48(3): 767-79.

38 Association of Official Analytical Chemists (AOAC). Official Methods of Analysis of AOAC International, 16th ed. Gaithersburg, MD: AOAC International, 1996.

39 Englberger L, Schierle J, Marks GC, Fitzgerald MH. Micronesian banana, taro, and other foods: newly recognized sources of provitamin A and other carotenoids. Journal of Food Composition and Analysis 2003; 16(1): 3-19.

40 Humphries JM, Khachik F. Distribution of lutein, zeaxanthin, and related geometrical isomers in fruit, vegetables, wheat, and pasta products. Journal of Agricultural and Food Chemistry 2003; 15(5): 1322-7.

41 Khachik F, Beecher GR, Whittaker NF. Separation, identification, and quantification of the major carotenoid and chlorophyll constituents in extracts of several green vegetables by liquid chromatography. Journal of Agricultural and Food Chemistry 1986; 34(4): 603-16.

42 World Health Organization (WHO)/Food and Agriculture Organization of the United Nations (FAO). Vitamin A. In: Human Vitamin and Mineral Requirements. Report of a Joint FAO/WHO Expert Consultation, Bangkok, Thailand. Rome: FAO/WHO, 2002.

43 Institute of Medicine. Dietary Reference Intakes for Vitamin A, Vitamin K, Arsenic, Boron, Chromium, Copper, Iodine, Iron, Manganese, Molybdenum, Nickel, Silicon, Vanadium, and Zinc. A Report of the Panel on Micronutrients, Subcommittees on Upper Reference Levels of Nutrients and of Interpretation and Use of Dietary Reference Intakes, and the Standing Committee on the Scientific Evaluation of Dietary Reference Intakes. Food and Nutrition Board. Washington, DC: National Academy Press, 2001.

44 Bingham H. A Gilbertese-English Dictionary. Boston, MA: American Board of Commissioners for Foreign Missions, 1953.

45 Rodriguez-Amaya DB. A Guide to Carotenoid Analysis in Foods. Washington, DC: ILSI Press, 1999.

46 Malolo M, Matenga-Smith T, Hughes R. The Staples We Eat. Noumea, New Caledonia: Secretariat of the Pacific Community, 1999. 